\title{
PAPERS
}

\section{Fate of Nissen fundoplication after 20 years. A clinical, endoscopical, and functional analysis}

M Luostarinen, J Isolauri, J Laitinen, M Koskinen, O Keyriläinen, H Markkula, E Lehtinen, A Uusitalo

\begin{abstract}
Of 46 patients who had Nissen fundoplication for proved gastro-oesophageal reflux, 25 were available for follow up after a median of 20 years, 15 had died of unrelated causes, and six could not be traced. All 25 patients in the follow up study were personally interviewed: 21 consented to an endoscopy, 14 to 24 hour recording of oesophageal $\mathrm{pH}$ and manometry, and 15 to radionuclide transit test. Repeat fundoplication for recurrent reflux was performed in two cases during the study. Heartburn and regurgitation were significantly lessened $(p<0 \cdot 005)$, but the incidence of dysphagia was slightly increased. Endoscopy showed six of 21 fundic wraps to be defective. Erosive oesophagitis was seen in two patients, and Barrett's oesophagus (histologically confirmed) in one of them and six other patients. Total reflux time was abnormal in four of 14 patients. No patient with an intact fundic wrap seen on endoscopy, only two of seven with Barrett's oesophagus, and one of four with abnormal reflux had oesophagitis. Fundoplication in itself did not affect oesophageal motility or transit, provided that the wrap was intact. It is concluded that Nissen fundoplication gave a reasonably good longterm effect in chronic reflux disease, with the state of the fundic wrap as the main determinant of outcome.
\end{abstract}

(Gut 1993; 34: 1015-1020)

Good longterm results of Nissen fundoplication have been reported, with disappearance of reflux symptoms in $80-97 \%$ of cases. ${ }^{2-6}$ Postfundoplication symptoms such as dysphagia, gas bloat, and epigastric pain may occur in variable degree, ${ }^{37-10}$ however, sometimes in a substantial number of patients. Previous studies on longterm results of fundoplication were based mainly on questioning patients, with only sporadic endoscopical examinations. ${ }^{2-46}$ Only a few reports concerned the fate of oesophagitis, and then with relatively short follow up, ${ }^{11} 12$ although the typical patient is young or middle aged and thus has a life expectancy of several decades. While shortterm evaluation after fundoplication, as a rule, shows normal values of 24 hour oesophageal $\mathrm{pH}$ measurements, ${ }^{1314}$ rise of lower oesophageal sphincter pressure $^{13 \text { is }}$ and probably correction of reflux induced disturbances of motility, ${ }^{16}{ }^{17}$ little is known of the longterm effects of fundoplication on oesophageal function.
The purpose of this study was to evaluate the longterm clinical and endoscopical effects of Nissen fundoplication performed for reflux, including assessment of oesophageal function.

\section{Patients and methods}

\section{PATIENTS}

The study group was taken from 46 consecutive patients operated on at our hospital for gastrooesophageal reflux during a two year period up to 1972. Evaluation before operation in all cases included upper gastrointestinal endoscopy, usually with oesophageal biopsy, cineradiography of the cardiac region, standard reflux test, and Bernstein-Baker test. ${ }^{18}$ In the standard test the oesophageal $\mathrm{pH}$ was monitored $5 \mathrm{~cm}$ above the manometrically defined lower sphincter during four provocations (deep breathing, Valsalva manoeuvre and cough, for three times, and Trendelenburg position for three minutes), when a fall to $\mathrm{pH}<4$ was considered to indicate reflux. Coronary disease as the cause of retrosternal symptoms was excluded in all cases by exercise electrocardiography. Reflux was seen in the standard test or at cinecardiography, or both in all cases, endoscopic oesophagitis in 16 (12 histologically confirmed), and 36 had positive Bernstein-Baker test.

The median age of the 29 men and 17 women was 52 (range 26-69) years at the time of fundoplication and their median weight 78 (56-103) $\mathrm{kg}$. None had connective tissue disease then or in the follow up period. All of the operations were performed by one of the authors (HM), using the Rossetti-Hell modification ${ }^{19}$ of the Nissen operation with concomitant hiatusplasty and pyloroplasty ${ }^{20}$ in all 46 patients, nonabsorbable sutures and fixation of the fundic wrap to the oesophagus. An 18 French gauge nasogastric tube was retained in the oesophagus during fundoplication. Five patients had additional selective gastric vagotomy because of excessive gastric acid secretion or a history of duodenal ulcer.

\section{FOLLOW UP}

The median study time after fundoplication was 20 (range 18-22) years. During this time 15 of 46 patients died of causes unrelated to the gastrooesophageal disease. Six others could not be traced. All the remaining 25 patients ( $54 \%$ of the 


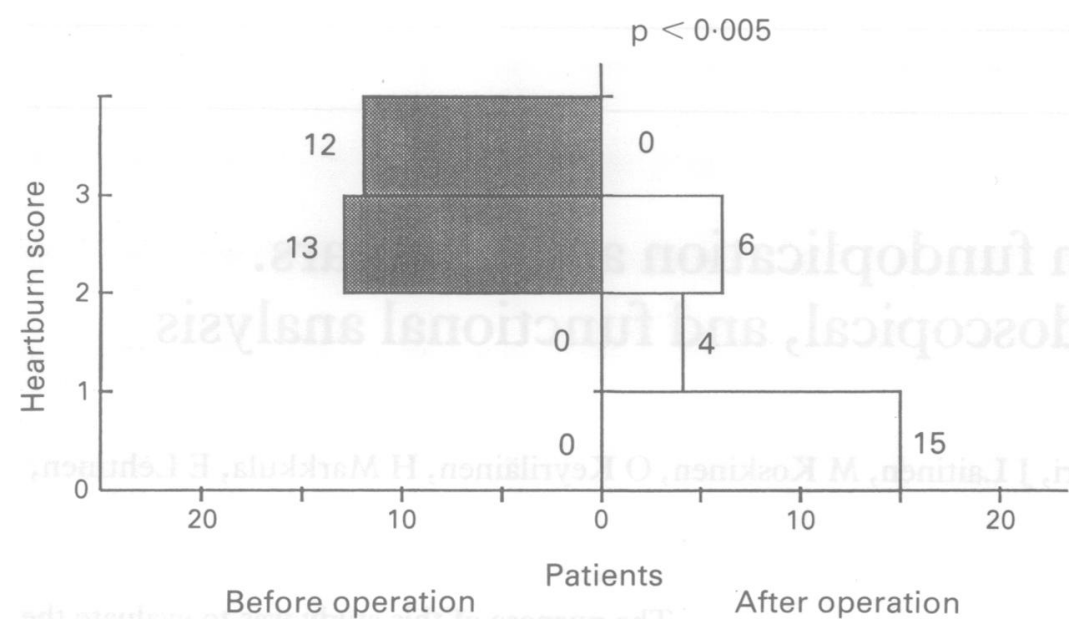

Figure 1: DeMeester-fohnson heartburn scores before and 20 years (median) after fundoplication $(n=25)$. Score fell in 23 cases and remained the same in two.

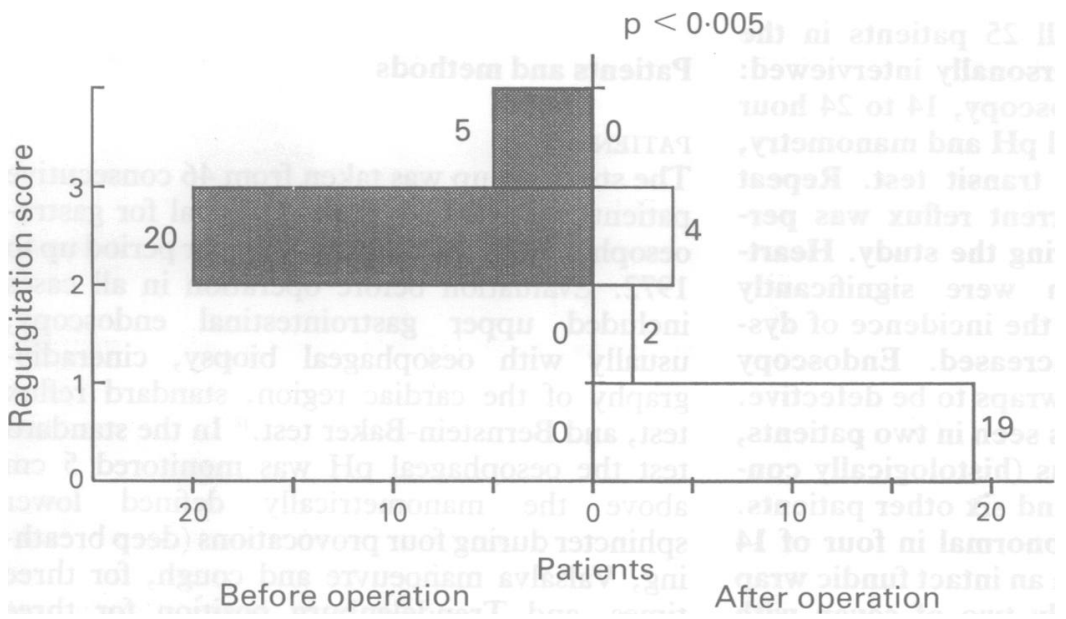

Figure 2: DeMeester-7ohnson regurgitation scores before and 20 years (median) after fundoplication $(n=25)$. Score fell in 21 cases and remained the same in four.

original 46 and $81 \%$ of the survivors) were interviewed according to a standard formula, using Visick grading ${ }^{21}$ of general clinical condition, recording heartburn, regurgitation and dysphagia with DeMeester-Johnson ${ }^{22} 23$ reflux scale. Postfundoplication increase of flatus, bloating, or epigastric pain was assessed by the patient as none, mild, moderate, or severe. Twenty one of 25 patients consented to have endoscopy, and 14 to 24 hour $\mathrm{pH}$ recording, ${ }^{24}$ standard reflux test, and oesophageal manometry. ${ }^{24}$ Oesophageal radionuclide transit ${ }^{25}$ was

TABLE I Symptoms leading to unsatisfactory Visick grades (3-4) in 11 of 25 cases

\begin{tabular}{|c|c|c|c|c|}
\hline Symptoms & $\begin{array}{l}\text { No of } \\
\text { cases }\end{array}$ & Background & $\begin{array}{l}\text { No of } \\
\text { cases }\end{array}$ & Remarks \\
\hline \multirow[t]{2}{*}{$\begin{array}{l}\text { Heartburn and } \\
\text { regurgitation }\end{array}$} & \multirow[t]{2}{*}{6} & $\begin{array}{l}\text { Defective fundic wrap } \\
\text { Gastritis }\end{array}$ & $\begin{array}{l}3 \\
1\end{array}$ & $\begin{array}{l}\text { Otherwise normal endoscopy and } \\
\text { function tests }\end{array}$ \\
\hline & & Impaired oesophageal motility & 1 & $\begin{array}{l}\text { Simultaneous contractions and } \\
\text { low peristaltic pressures in } \\
\text { distal oesophagus - prolonged } \\
25 \% \text { emptying time }\end{array}$ \\
\hline \multirow[t]{2}{*}{ Epigastric pain } & \multirow[t]{2}{*}{4} & $\begin{array}{l}\text { Unknown } \\
\text { Recurrent reflux }\end{array}$ & $\begin{array}{l}1 \\
1\end{array}$ & $\begin{array}{l}\text { Intact fundic wrap, normal } \\
\text { motility but total reflux time } \\
12 \cdot 5 \%\end{array}$ \\
\hline & & $\begin{array}{l}\text { Ventral hernia } \\
\text { Intra-abdominal adhesions } \\
\text { Unknown }\end{array}$ & $\begin{array}{l}1 \\
1 \\
1\end{array}$ & Relief after adhesiotomy \\
\hline Diarrhoea & 1 & Concomitant vagotomy & 1 & \\
\hline
\end{tabular}

evaluated in 15 patients and a barium meal was performed in five cases to confirm endoscopical findings.

During the study time two patients had had repeat fundoplication for recurrent reflux and oesophagitis associated with defective fundic wrap. Before the second operation all examinations except 24 hour $\mathrm{pH}$ measurements and radionuclide transit were repeated and the results are included in the analysis of the subgroup with defective fundic wrap.

All the postoperative endoscopies were performed by one of the authors (ML). SavaryMiller grading ${ }^{26}$ of the oesophageal mucosa was confirmed by biopsy specimens ${ }^{27}$ taken from all macroscopic lesions and also a few centimetres proximal to them or, if no lesions were visible, from a site $3-5 \mathrm{~cm}$ above the oesophagogastric junction. Presence of gastric type epithelium (histologically confirmed) more than $3 \mathrm{~cm}$ above the most cranial fold of the gastric mucosa was considered to indicate Barrett's oesophagus. The state of the fundic wrap was checked with retroflexed endoscope. ${ }^{5}$

Slipping was registered when there was a distinct gastric pouch above the narrowing caused by the folds of the wrap, and disruption implied no visible folds or only distorted, loose folds at the oesophagogastric junction. Abnormal reflux was defined as $\mathrm{pH}<4$ for more than $4 \cdot 2 \%$ of the recording time. ${ }^{28}$ Non-specific disorders of motility were manometrically classified with Castell criteria. ${ }^{29}$ The pressure in and length of the lower oesophageal sphincter were assessed with rapid pull through technique. ${ }^{24} 30$ In radionuclide transit the calculated indices ${ }^{25}$ were the time when $5 \%$ and $90 \%$ of the radionuclide dose appeared in the stomach, emptying time of the distal oesophageal third to $25 \%$ activity value, mean transit time, and residual activity in the distal third. The values were compared with findings in $\mathbf{1 0}$ healthy controls. Two standard deviations above the control means constituted the upper limit of normality.

\section{STATISTICS}

Differences between scored data were checked with Fisher's exact test. Wilcoxon signed rank test was used to compare pre with postoperative figures and the Mann-Whitney $U$ test to analyse differences between subgroups and controls in symptom scores and results of function tests.

\section{Results}

At follow up the Visick symptom grade was excellent in five of 25 patients and good in nine, while eight patients had grade 3 and three grade 4. Reflux symptoms were the main reason for unsatisfactory grades (Table I). All but the patients with grade 4 had subjectively benefited from the operation, and 19 of 25 unhesitatingly declared willingness to repeat the operation in a similar preoperative situation.

Heartburn and regurgitation were significantly ( $<<0.005)$ diminished (Figs 1 and 2). On DeMeester-Johnson clinical score, 15 of 25 patients had no reflux, while eight reported mild and two moderately severe symptoms. Heart- 


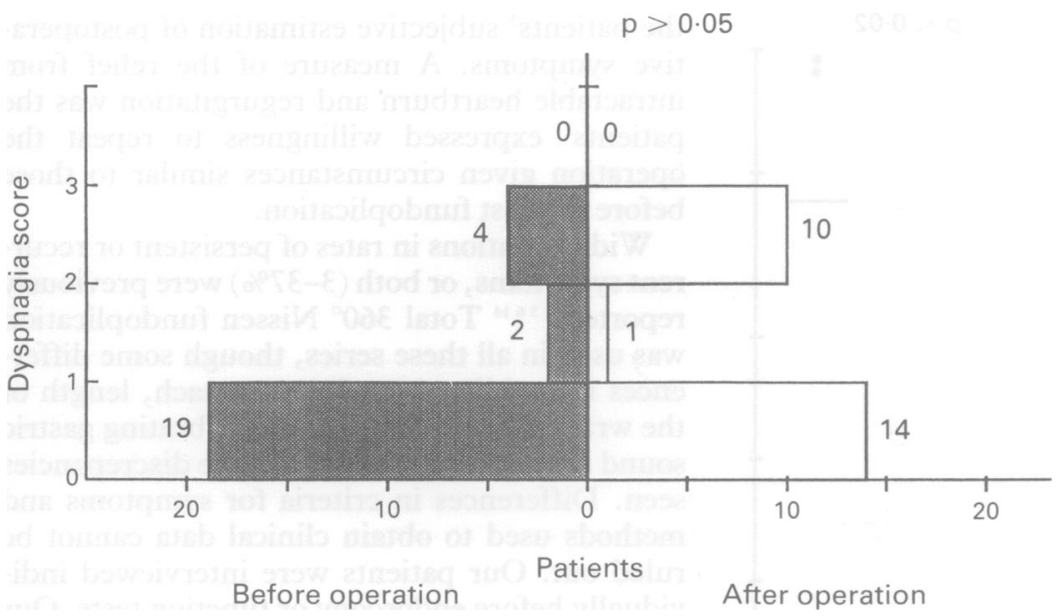

Figure 3: DeMeester-Fohnson dysphagia scores before and 20 years (median) after fundoplication $(n=25)$. Score fell in five cases, remained the same in 10 , and rose in 10.

burn or regurgitation, or both were less common in the patients with endoscopically intact fundic wrap than in those with defective wrap $(15 \% v$ $50 \%$ ). The onset time of recurrent symptoms could be identified by five patients - that is 4 months, 15, 17, 19, and 19 years after fundoplication. The incidence of dysphagia was slightly increased (Fig 3), especially in the patients with intact $v$ defective wrap (60\% v 33\%). Dysphagia was only occasional, except in four patients with regular (daily or weekly) episodes. All patients ate normal food, but some reported more thorough mastication and slower swallowing than before.

Twelve patients had increased flatus (nine cases) and/or bloating (nine cases) at follow up. Three of the total 12 with these symptoms assessed them as moderately disturbing and only one as severe. Ten were unable to vomit $(62 \%$ of those who had tried), and 15 had impaired belching (described as impossible by seven and difficult by eight). Only inability to belch was associated with the state of the fundic wrap,

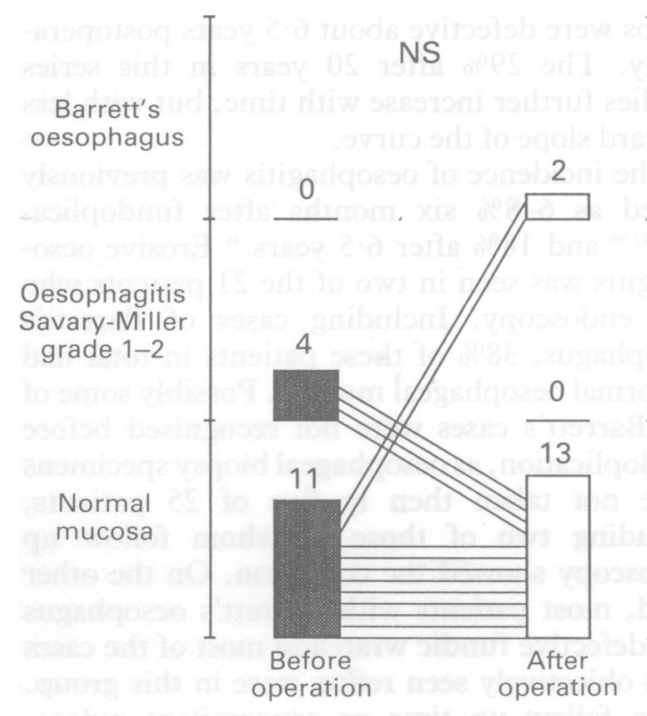

Intact fundic wrap

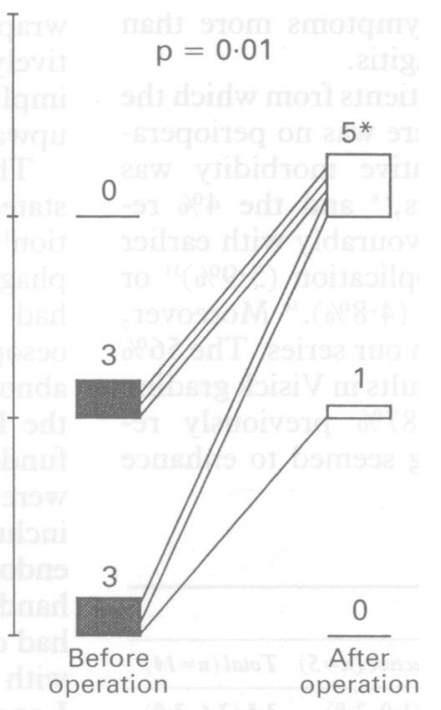

Defective fundic wrap
Figure 4: State of oesophageal mucosa at endoscopy 20 years (median) after fundoplication in patients with intact $(n=15)$ or defective $(n=6)$ fundic wrap. All present findings histologically confirmed. Biopsy specimens before the operation not available in five cases. Significant intergroup difference $(p=0.002)$ after, but not before fundoplication. One patient with Barrett's oesophagus also had erosive oesophagitis. * being twice as common in cases with intact $v$ defective wrap.

Sliding hiatal hernia had been seen at preoperative cineradiography in 16 of 21 patients with follow up endoscopy, but no paraoesophageal hernia. Two recurrent hiatal hernias were now found, both together with defective fundal wrap, and one paraoesophageal hernia associated with epigastric pain.

Preoperatively seven patients had endoscopic oesophagitis (Savary-Miller grades 1-2), histologically confirmed in six cases. At follow up abnormal oesophageal mucosa was seen in eight patients, all with corresponding histology (Fig 4 ), and including two cases of grade 2 oesophagitis, one of them concomitant with Barrett's oesophagus. Three of the fundic wraps in these 21 cases had slipped and three were disrupted. Chronic superficial gastritis was seen in 12 patients and atrophic gastritis in two. Free duodenogastric bile reflux was seen in two cases, but the pylorus was deformed in all 21 and was wide open constantly in 16 .

Standard reflux test had been positive before operation in 16 of 21 patients with follow up endoscopy. One patient had had a positive test before repeat fundoplication, but was now reflux free, and the test was positive in only two patients. In 24 hour $\mathrm{pH}$ recording the total reflux time was abnormal at follow up in four of 14 patients, including three with defective fundic wrap (Fig 5). Two of four, and one with $3 \cdot 1 \%$ total acid reflux time and defective wrap, clearly had alkaline reflux $(\mathrm{pH}>7$ for $3 \cdot 1-6 \%$ of the recording time).

At oesophageal manometry the values for lower oesophageal sphincter pressure and peristaltic amplitudes were higher in patients with intact $v$ defective fundic wrap, but the differences were not statistically significant (Table II).

In radionuclide transit the times of the appearance of $5 \%$ and $90 \%$ of the isotope in the stomach differed significantly $(\mathrm{p}<0.02$ and $\mathrm{p}<0.05)$ between the 15 patients who were tested and the healthy controls (Fig 6). Most of the abnormal values were found in patients with defective fundic wrap. Barrett's oesophagus was associated with slightly $(p=0.03)$ enhanced residual activity in the distal oesophagus: median $4.3 \%$ (interquartile range $2-5 \cdot 6 \%) v 8 \cdot 3 \%(4 \cdot 6-14 \%)$.

\section{Discussion}

Good antireflux effects of Nissen fundoplication were evident 20 years after the operation, provided that the fundic wrap was still intact. Objective recurrence of reflux was found in only one patient with endoscopically intact wrap. Defective wrap was found at follow up in six of 21 patients who were examined.

For the following reasons this case series seems suitable for evaluating the longterm results of Nissen fundoplication. The patients were consecutively referred for surgery by the same gastroenterologist $(\mathrm{OK})$, thorough investigations before operation objectively confirmed gastro-oesophageal reflux, all operations were performed with standardised technique by one surgeon, and all revisional oesophageal surgery in the region was done at our hospital. This 


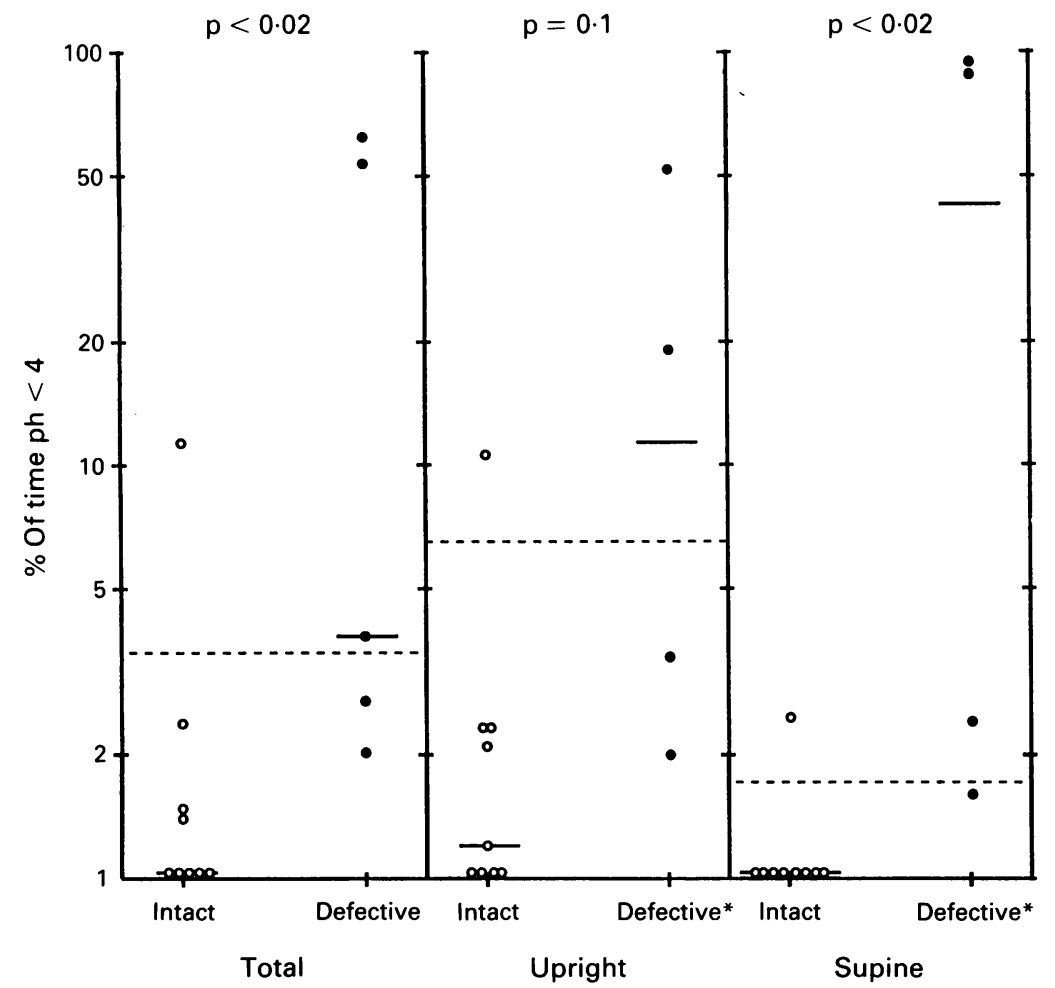

Figure 5: 24 hour $p H$ recordings 20 (median) years after fundoplication in nine patients with intact, and five with defective fundic wrap. Median = short transverse line, .... =upper normal limits. ${ }^{28} \star$ One patient with defective wrap did not complete her diary.

makes it highly unlikely that any further operations would be unknown to us. The use of concomitant pyloroplasty ${ }^{20}$ (no longer recommended) and retention of a relatively small-bore sound in the oesophagus during fundoplication $^{4531}$ may have been contributing factors in some postoperative conditions such as dysphagia ${ }^{458}$ and gastritis, ${ }^{32}$ but should not have influenced the antireflux efficacy of fundoplication. It seems noteworthy that these patients were operated on before the advent of $\mathrm{H}_{2}$ blocker treatment, and consequently the indication for surgery, in contrast with current practice, tended to be intractable symptoms more than treatment resistant oesophagitis.

In the total series of 46 patients from which the 25 patients were taken, there was no perioperative death, the postoperative morbidity was similar to previous reports, ${ }^{46}$ and the $4 \%$ reoperation rate compares favourably with earlier figures after Nissen fundoplication $(5.9 \%)^{33}$ or Belsey Mark IV operation (4.8\%). ${ }^{34}$ Moreover, the study time was longer in our series. The $56 \%$ excellent or good overall results in Visick grading was lower than the $67-87 \%$ previously reported. ${ }^{23} 35$ Visick grading seemed to enhance

TABLE II Oesophageal manometry at follow up

\begin{tabular}{|c|c|c|c|}
\hline \multirow{2}{*}{$\begin{array}{l}\text { Indices } \\
\text { Median (interquartile range) }\end{array}$} & \multicolumn{3}{|l|}{ Fundic wrap } \\
\hline & Intact $(n=9)$ & Defective $(n=5)$ & Total $(n=14)$ \\
\hline $\begin{array}{l}\text { Lower oesophageal pressure }(\mathrm{kPa}) \\
\text { Lower oesophageal sphincter length }(\mathrm{cm}) \\
\text { Mean oesophageal peristaltic amplitude }(\mathrm{kPa}) \\
\text { Distal oesophageal peristaltic amplitude }(\mathrm{kPa})\end{array}$ & $\begin{array}{l}3 \cdot 7(3 \cdot 3-4 \cdot 5) \\
4 \cdot 5(3 \cdot 6-6 \cdot 3) \\
8 \cdot 8(7 \cdot 1-12 \cdot 3) \\
10 \cdot 3(7 \cdot 2-16 \cdot 0)\end{array}$ & $\begin{array}{l}2 \cdot 6(1 \cdot 9-2 \cdot 8) \\
4 \cdot 2(3 \cdot 8-5 \cdot 0) \\
3 \cdot 9(3 \cdot 4-6 \cdot 9) \\
4 \cdot 3(2 \cdot 8-7 \cdot 2)\end{array}$ & $\begin{array}{l}3 \cdot 5(2 \cdot 6-3 \cdot 9) \\
4 \cdot 2(3 \cdot 7-5 \cdot 8) \\
7 \cdot 6(5 \cdot 3-11 \cdot 8) \\
8 \cdot 1(4 \cdot 3-11 \cdot 2)\end{array}$ \\
\hline $\begin{array}{l}\text { Duration of peristalitic amplitude in distal } \\
\text { oesophagus }(s)\end{array}$ & $4 \cdot 6(3 \cdot 7-6 \cdot 8)$ & $5 \cdot 0(4 \cdot 4-5 \cdot 3)$ & $4 \cdot 9(3 \cdot 5-6 \cdot 5)$ \\
\hline $\begin{array}{l}\text { Non-specific oesophageal motility disorder, } \\
\text { No }(\%)\end{array}$ & $3 \cdot 0(33)$ & $3 \cdot 0(60)$ & $6 \cdot 0(43)$ \\
\hline
\end{tabular}

the patients' subjective estimation of postoperative symptoms. A measure of the relief from intractable heartburn and regurgitation was the patients' expressed willingness to repeat the operation given circumstances similar to those before the first fundoplication.

Wide variations in rates of persistent or recurrent symptoms, or both (3-37\%) were previously reported. ${ }^{25614}$ Total $360^{\circ}$ Nissen fundoplication was used in all these series, though some differences in mobilisation of the stomach, length of the wrap, and diameter of the calibrating gastric sound may have contributed to the discrepancies seen. Differences in criteria for symptoms and methods used to obtain clinical data cannot be ruled out. Our patients were interviewed individually.before endoscopy or function tests. Our finding of slow accumulation of cases confirmed earlier results, ${ }^{2}$ with regard to the interval to the start of recurrent symptoms. Symptoms, however, do not always imply objectively demonstrable reflux, ${ }^{37}$ particularly after antireflux surgery. In one series only one third of patients complaining of heartburn or regurgitation two years after fundoplication and had abnormal 24 hour $\mathrm{pH}$ score. ${ }^{14}$ In two of our symptomatic patients endoscopy and 24 hour $\mathrm{pH}$ recordings were normal. Two others refused function tests, but were endoscopically normal.

Dysphagia among our patients was similar to figures stated after similarly modified fundoplication. $^{39}$ Shorter and floppier fundoplication gavie distinctly lower figures. ${ }^{46}$ Dysphagia caused by an excessively tight wrap ${ }^{8}$ should be most evident when the wrap is intact, but in all of our patients with dysphagia and intact wrap the symptoms were occasional and not disturbing unless there was some other abnormality (Barrett's oesophagus, oesophagitis or impaired gastro-oesophageal function).

The state of the fundic wrap can be accurately assessed with the retroflexed endoscope, ${ }^{58}$ and shortly after fundoplication $8-9 \%$ of wraps were found to be defective. ${ }^{3639}$ In a previous study from our hospital, ${ }^{38} 24$ of 105 fundoplication wraps were defective about 6.5 years postoperatively. The $29 \%$ after 20 years in this series implies further increase with time, but with less upward slope of the curve.

The incidence of oesophagitis was previously stated as $6-8 \%$ six months after fundoplication $^{12}{ }^{36}$ and $18 \%$ after 6.5 years. ${ }^{38}$ Erosive oesophagitis was seen in two of the 21 patients who had endoscopy. Including cases of Barrett's oesophagus, $38 \%$ of these patients in total had abnormal oesophageal mucosa. Possibly some of the Barrett's cases were not recognised before fundoplication, as oesophageal biopsy specimens were not taken then in five of 25 patients, including two of those in whom follow up endoscopy showed the condition. On the other hand, most patients with Barrett's oesophagus had defective fundic wrap and most of the cases with objectively seen reflux were in this group. Long follow up time or concomitant pyloroplasty, or both, and thus possibly increased bile reflux,${ }^{40+1}$ may have influenced the incidence of Barrett's oesophagus.

Abnormal total reflux time (24 hour $\mathrm{pH}$ recording) in four of 14 patients studied con- 


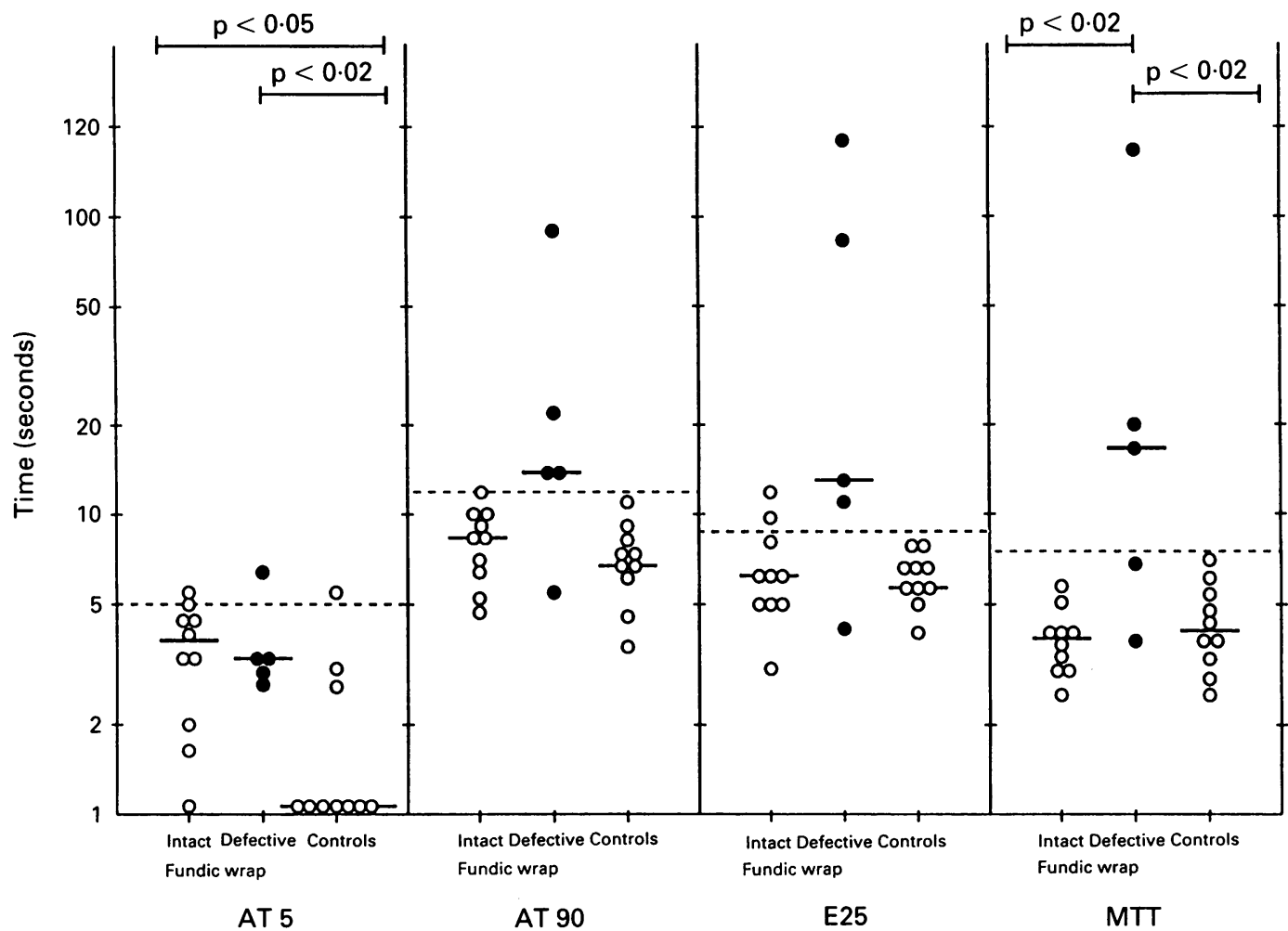

Figure 6: Radionuclide transit in 10 normal controls and 20 years (median) after fundoplication in 10 patients with intact, and five with defective fundic wrap. Median= short transverse line. = control mean + two standard deviations. AT 5 and AT $90=$ time (in seconds) when 5\% and 90\%, respectively, of the radionuclide dose appeared to the stomach. E 25=emptying time of the distal oesophageal third to $25 \%$ activity values. $M T T=$ mean transit time in the distal oesophageal third.

trasts with about a $10 \%$ incidence 6 months2 years after fundoplication. ${ }^{1436}$ One of the patients with normal test result at follow up had had erosive oesophagitis before repeat fundoplication, presumably with abnormal reflux (not measured). Inclusion of this case brings the total with abnormal reflux time to five (about 33\%). Although many patients refused $\mathrm{pH}$ recording, this figure seems reliable, as only one patient with defective wrap was not studied and the incidence of reflux symptoms was equal in the groups with and without $\mathrm{pH}$ measurement. The fact that only one patient with intact wrap had abnormal reflux accords with a previous report ${ }^{36}$ of such reflux in only about $3 \%$ patients with endoscopically intact wrap. Partially defective wrap, however, did not inevitably lead to abnormal reflux in our patients. Good results seen after partial fundoplication ${ }^{34} 35$ show that a full $360^{\circ}$ wrap is not the only condition needed for effective antireflux action.

That fundoplication in itself does not always disturb oesophageal motility or emptying, even long-term, was evident from manometry and radionuclide transit. Almost all the abnormal values were found in patients with defective fundic wrap. The slight increase of residual activity associated with Barrett's oesophagus may have been partly a result of the uptake of isotype by the Barrett mucosa, ${ }^{+2}$ but this residual activity did not interfere with calculation of the transit indices. ${ }^{25}$

In conclusion, the results of Nissen fundoplication for chronic gastro-oesophageal reflux were reasonably good 20 years after the operation. The recurrence rate was similar to that reported after two years' treatment with omeprazole. ${ }^{+3}$
As recurrence may appear many years atter the operation, however, long - though not particularly frequent - follow up is required. Fundoplication has some adverse effects, but in most cases these are mild and well compensated by lasting relief of heartburn and regurgitation. Some reported postoperative symptoms are related to surgical technique, and seem able to be reduced by slight modifications, ${ }^{4531}$ which probably also lessen the risk of wrap disruption. We therefore recommend Nissen fundoplication in the management of gastro-oesophageal reflux as giving better subjective and objective longterm relief than any other antireflux measure. If oesophagitis is not relieved by conservative treatment, the operation should be performed before oesophageal function is severely damaged. ${ }^{38445}$

This study was financially aided by grants from the Tampere Tuberculosis Foundation, the Emil Aaltonen Foundation, and the Academy of Finland.

1 Nissen R. Eine einfache Operation zur Beeinflussung de Refluxösophagitis. Schweiz Med Wochenschr 1956; 86: $590-2$.

2 Negre JB, Markkula HT, Keyrilainen O, Matikainen $M$. Nissen fundoplication: results at 10 year follow-up. $A m \dot{\mathcal{F}}$ Nissen fundoplication:
Surg 1983; 146: 635-8.

3 Ackermann Ch, Margareth L, Müller C, Harder F. Symptoms 10-20 years after fundoplication. In: Siewert JR, Hölscher $\mathrm{AH}$, eds. Diseases of the esophagus. Berlin, Heidelberg: Springer Verlag, 1988: 1198-202.

4 DeMeester TR, Bonavina L, Albertolucci M. Nissen fundoplication for gastroesophageal reflux disease. Ann Surg 1986; 204: 9-20.

5 Donahue PE, Samuelson S, Nyhus LM, Bombeck T. The floppy Nissen fundoplication. Arch Surg 1985; 120: 663-8.

6 Schirazi SS, Schulze K, Soper RT. Long-term follow-up for treatment of complicated chronic reflux esophagitis. Arch Surg 1987; 122: 548-52.

7 Woodward ER, Thomas HF, McAlhany JC. Comparison of crural repair and Nissen fundoplication in the treatment of esophageal hiatus hernia with peptic esophagitis. Ann Surg 1971; 173: 782-9.

8 Skinner DB. Complications of surgery for gastroesophageal reflux. World ₹ Surg 1977; 1: 485-92. 
9 Negre JB. Post-fundoplication symptoms. Do they restrict the success of Nissen fundoplication? Ann Surg 1983; 198: 689-700.

10 Low DE, Mercer CD, James EC, Hill LD. Post Nissen syndrome. Surg Gynecol Obstet 1988; 167: 1-5.

11 Spechler SI. The Department of Veterans Affairs Gastroesophageal Reflux Disease Study Group. Comparison of medical and surgical therapy for complicated gastroesophageal reflux disease in veterans. $N$ Engl f Med 1992 326: 786-92.

12 Johnsson $F$, Joelsson B, Gudmundsson $\mathrm{K}$, Florén $\mathrm{C}-\mathrm{H}$ Walther B. Effects of fundoplication on the antireflux Walther B. Effects of fundoplication

13 DeMeester TR, Johnson LF. Evaluation of the Nissen antireflux procedure by esophageal manometry and twenty-fou hour pH monitoring. Am $\mathcal{F}$ Surg 1975; 129: 94-100.

14 Breumelhof R, Smout AJPM, Schyns MWRJ, Bronzwaer PWA, Akkermanas LMA, Jansen A. Prospective evaluation of the effects of Nissen fundoplication on gastroesophagea reflux. Surg Gynecol Obstet 1990; 171: 115-9.

15 Ellis FH, Crozier RE. Reflux control by fundoplication: A clinical and manometric assessment of the Nissen operation. Ann Thorac Surg 1984; 38: 387-91.

16 Gill RC, Bowes KL, Murphy PD, Kingma YJ. Esophageal motor abnormalities in gastroesophageal reflux and the effects of fundoplication. Gastroenterology: 1986; 91: 364-9.
Ortiz AO, Martinez de Hero LF, Parrilla PP, Aguayo JL, Garcia JA, Morales GC. Surgery improves defective oesophageal peristalsis in patients with gastro-oesophagea reflux. Br F Surg 1991; 78: 1095-7.

18 Bernstein LM, Baker LA. A clinical test for esophagitis. Gastroenterology 1958; 34: 760-81

19 Rossetti M, Hell K. Fundoplication for treatment of gastroesophageal reflux in hiatus hernia. World f Surg 1977; 1 : 439-44

20 Berman JK, Berman EJ. Balanced operations for esophagitis associated with oesophageal hiatal hernia. Arch Surg 1959, 78: 889-96.

21 Visick AH. Measured radical gastrectomy. Review of 505 operations for peptic ulcer. Lancet 1948; i: 505-10.

22 DeMeester TR, Johnson LF, Joseph GJ, Toscano MS, Hall AW, Skinner DB. Patterns of gastroesophageal reflux in AW, Skinner DB. Patterns of gastroesophage

23 DeMeester TR, Johnson LF. The evaluation of objective measurements of gastroesophageal reflux and their contribuion to patient management. Surg Clin North Am 1976; 56 : 39-53

24 Isolauri J, Reinikainen P, Markkula H. Functional evaluation of interposed colon in esophagus. Acta Chir Scand 1987; 153: $21-4$

25 Isolauri J, Koskinen MO, Markkula H. Radionuclide transit in patients with colon interposition. $\mathcal{F}$ Thorac Cardiovas Surg 1987; 94: 521-5.

26 Savary M, Miller G. Der oesophagus, lehrbuch und endoskopischer atlas. Solothurn: Gassmann, 1977.

27 Ismail-Beigi F, Horton PF, Pope CE II. Histological consequences of gastroesophageal reflux in man. Gastroenterology 1970; 58: 163-74.
28 Johnson LF, DeMeester TR. Twenty-four-hour pH monitoring of the distal esophagus. Am 7 Gastroenterol 1974; 62: 325-32.

29 Castell DO. The nutcracker esophagus and other primary esophageal motility disorders. In: Castell DO, Richter JE, Dalton CB, eds. Esophageal motility testing. New York: Elsevier, 1987: 130-42.

30 Dalton CB. Measurements and interpretations. In: Castell DO, Richter JE, Dalton CB, eds. Esophageal motility DO, Richter JE, Dalton CB, eds. E
testing. New York: Elsevier, 1987: 61-78.

31 Siewart JR, Feussner H, Walker SJ. Fundoplication: How to do it? Periesophageal wrapping as a therapeutic principal in gastroesophageal reflux. World f Surg 1992; 16: 326-34.

32 Cooperman AM. Postoperative alkaline reflux gastritis. Surg Clin North Am 1976; 56: 1445.

33 Skinner DB. Surgical management after failed antireflux operations. World F Surg 1992; 16: 359-63.

34 Orringer M, Skinner D, Belsey R. Long-term results of the Mark IV operation for hiatal hernia and analyses of recurrences and their treatment. F Thorac Cardiovasc Surg 1972 63: 25 .

35 Thor K, Silander T. A long-term randomized prospective trial of the Nissen procedure versus a modified Toupet technique. Ann Surg 1989; 210:719 24 .

36 O'Hanrahan T, Marples M, Bancewicz J. Recurrent reflux and wrap disruption after Nissen fundoplication: detection, wrap disruption after Nissen fundoplication:
incidence and timing. Br $\mathcal{Y}$ Surg 1990; 77: 545-7.

37 Johnsson F, Joelsson B, Gudmundsson $\mathrm{K}$, Greiff $\mathrm{L}$ Symptoms and endoscopic findings in the diagnosis of gastroesophageal reflux disease. Scand $\mathcal{F}$ Gastroenterol 1987; 22: 714-8.

38 Luostarinen M. Nissen fundoplication for reflux esophagitis: long-term clinical and endoscopic results in 109 of 127 consecutive cases. Ann Surg 1993; 217: 329-37.

39 Feussner H, Petri A, Walker S, Bollschweiler E, Siewert JR. The modified AFP score: an attempt to make the results of anti-reflux surgery comparable. Br f Surg 1991; 78: $942-6$.

40 Meyer W, Vollmar F, Bär W. Barrett-esophagus following total gastrectomy. Endoscopy 1979; 2: 121-6.

41 DeMeester TR, Attwood SEA, Smyrk TC, Therkildsen DH, Hinder RA. Surgical therapy in Barrett's esophagus. Ann Surg 1990; 212: 528-42.

42 Polepalle SC, McCallum RW. Barrett's esophagus, curren assessment and future perspectives. Gastroenterol Clin North Am 1990; 19: 733-44.

43 Klinkenberg-Knol EC, Jansen JBMJ, Lamers CBHW, Nelis $F$, Snel P, Meuwissen SGM. Use of omeprazole in the management of reflux esophagitis resistant to $\mathrm{H}_{2}$-receptor antagonists. Scand 7 Gastroenterol 1989; 24: (suppl 166): 88-93.

44 Kahrilas PJ, Dodds WJ, Hogan WJ, Kern M, Arndorfer RC, Reece A. Esophageal peristaltic dysfunction in peptic esophagitis. Gastroenterology 1988; 94: 73-80.

45 Zaninotto G. De Meester TR, Bremner CG, Smyrk TC, Cheng Shih-Chuan. Esophageal function in patients with reflux induced strictures and its relevance to surgical treatment. Ann Thorac Surg 1989; 47: 362-70. 